"A case study of global agency innovation rankings: implications on current definitions of innovation"

\begin{tabular}{|c|c|c|}
\hline AUTHORS & \multicolumn{2}{|c|}{ Lotfi Belkhir (D https://orcid.org/0000-0001-6852-2065 } \\
\hline ARTICLE INFO & \multicolumn{2}{|c|}{$\begin{array}{l}\text { Lotfi Belkhir and Mary Mathew (2018). A case study of global agency innovation } \\
\text { rankings: implications on current definitions of innovation. Problems and } \\
\text { Perspectives in Management, 16(3), 269-284. doi:10.21511/ppm.16(3).2018.22 }\end{array}$} \\
\hline DOI & \multicolumn{2}{|c|}{ http://dx.doi.org/10.21511/ppm.16(3).2018.22 } \\
\hline RELEASED ON & \multicolumn{2}{|l|}{ Wednesday, 15 August 2018} \\
\hline RECEIVED ON & \multicolumn{2}{|l|}{ Monday, 09 April 2018} \\
\hline ACCEPTED ON & \multicolumn{2}{|l|}{ Tuesday, 10 July 2018} \\
\hline LICENSE & \multicolumn{2}{|c|}{$\begin{array}{l}\text { This work is licensed under a Creative Commons Attribution-NonCommercial } 4.0 \\
\text { International License }\end{array}$} \\
\hline JOURNAL & \multicolumn{2}{|c|}{ "Problems and Perspectives in Management" } \\
\hline ISSN PRINT & \multicolumn{2}{|l|}{$1727-7051$} \\
\hline ISSN ONLINE & \multicolumn{2}{|l|}{$1810-5467$} \\
\hline PUBLISHER & \multicolumn{2}{|c|}{ LLC “Consulting Publishing Company "Business Perspectives" } \\
\hline FOUNDER & \multicolumn{2}{|c|}{ LLC "Consulting Publishing Company "Business Perspectives" } \\
\hline & & $\begin{array}{l}\text { ニ-: } \\
\text { =-:- }\end{array}$ \\
\hline NUMBER OF REFERENCES & NUMBER OF FIGURES & NUMBER OF TABLES \\
\hline 31 & 2 & 5 \\
\hline
\end{tabular}

(C) The author(s) 2022. This publication is an open access article. 


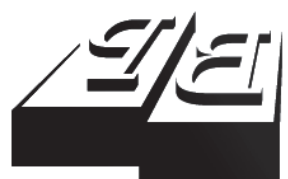

BUSINESS PERSPECTIVES

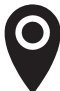

LLC "CPC "Business Perspectives" Hryhorii Skovoroda lane, 10, Sumy, 40022, Ukraine

www.businessperspectives.org

Received on: $9^{\text {th }}$ of April, 2018 Accepted on: $10^{\text {th }}$ of July, 2018

(c) Lotfi Belkhir, Mary Mathew, 2018

Lotfi Belkhir, Ph.D., Associate Professor, W. Booth School of Engineering Practice \& Technology, McMaster University, Canada.

Mary Mathew, Dr., Ph.D., Technology \& Innovation Consultant, Toronto, Canada.

\section{A CASE STUDY OF GLOBAL AGENCY INNOVATION RANKINGS: IMPLICATIONS ON CURRENT DEFINITIONS OF INNOVATION}

\begin{abstract}
In this paper, the authors analyze global innovation rankings as provided by Strategy\& over the last 7 years. They first explore the raw ranks and report variations in year-overyear (YOY) ranks for top ten ranking companies. The normalized innovation ranks are then used to calculate the Innovation Power (inP) to assess if these companies maintained or improved their ranks over time. An interesting classification of innovations for the top 10 emerges from this analysis. The constant top innovators were Apple and Google. The rising innovators were Tesla, $3 \mathrm{M}$ and Facebook. Other classifications are discussed. The authors propose a non-statistical predictive model, which is reminiscent of a kinematic model using a novel concept of Innovation Momentum (inM) and predict that for 2017, Apple and Google will hold their first and second place, followed by Amazon, Samsung and Tesla. Facebook is also expected to rise in its rank. Companies that reach out and serve end-user needs with service innovations appear rising in ranks, far more than R\&D intensive patent filing innovators in these ranks. Tesla is an interesting top ranker to watch. There are implications for software focused companies gaining importance given their flexibility over hardware dominant ones. Some bottom innovators are further declining. Although the rankings are perceptionbased, there is a pattern that implies it is not random or merely subjective. The analysis highlights the need for leaders and consultants to put in perspective the complex management problem of measuring innovation.
\end{abstract}

\section{Keywords}

JEL Classification innovation management, innovation ranking, innovation model, innovation momentum, R\&D spending

\section{INTRODUCTION}

As strategically important and as commonly used as it is, the definition of innovation remains vague and muddy in most cases. Used loosely by practitioners, it is often assumed to imply worthwhile activities involving creativity, research and development, inventiveness and new ventures. It is important to all, but has a different meaning to each. In scholarly circles, however, there have been extensive attempts to provide a general definition for innovation. In the Schumpeterian view, it's often equated with entrepreneurship (Schumpeter, 2000), while in established companies, it is usually equated with the introduction of new technical methods, products, sources of supply, processes and forms of industrial organization (Rogers, 1995). Innovation is usually measured by R\&D intensity, number of patents granted and number of knowledge workers involved. It is often regarded as the exclusive realm of scientists and engineers that are dedicated to changing the world with their creativity and inventiveness. This remains, by far, the most prevalent understanding of what constitutes innovation, and forms the basis of most definitions thereof. For fewer authors,
This is an Open Access article, distributed under the terms of the Creative Commons Attribution-NonCommercial 4.0 International license, which permits re-use, distribution, and reproduction, provided the materials aren't used for commercial purposes and the original work is properly cited. 
innovation reflects a more "strategic intent" (Prahalad, 1989) and takes a more market-pull approach. Conceptually, it is tightly linked with the outcome, as opposite to the outputs or the process, which is the successful commercialization of inventions and other intellectual property to gain a strong competitive advantage. This business model-based, market-driven definition of innovation has been further expanded by Gary Hamel (Hamel, 1998) and Henry Chesbrough (Chesbrough, 2010). The latter points out that a better business model, such as Wal-Mart in retailing, Dell in PC's or Southwest Airlines will often beat a better technology from a competitor. In sum, however, all these definitions of innovation revolve around a "multi-stage process whereby organizations transform ideas into new/improved products, service or processes, to advance, compete and differentiate themselves successfully in their marketplace" (Baregheh, Rowley, \& Sambrook, 2009).

Novel changes in an organization also signify innovation in some instances. Innovation may involve a wide range of different types of change depending on the organization's resources, capabilities, strategies, and requirements (Baregheh, Rowley, \& Sambrook, 2009). Organizations use innovation as a tool in order to influence an environment or manage their changing environments, internal and external (Damanpour, 1991). Thus, organizations that communicate their changes whether in leadership, organizational, technological, product or services to the outer world will be seen as being innovative compared to those who remain in status quo.

Nevertheless, it is clear that the definition of innovation operationalizes the measurement of innovation, wherein we can assume that knowledge about the definition of innovation has bearing on how a sample will rate innovation of companies. However, although the term innovation is strategically important and commonly used, the definition of innovation remains vague because of the way it evolved amongst scholars and practitioners.

In sum, all the above research suggests that the definition and understanding of innovation is almost always implicit and hence vague and up to the "eye of the beholder", and even cases where innovation is still equated to invention (Wang \& Kleppe, 2001).

In this paper, we take a markedly different and purely empirical approach to understanding what innovation means. We examine patterns in innovative ranks year-over-year (YoY) as ranked by participants in the ranking process by the $\mathrm{PwC}$ agency called Strategy\&, involving executives from the 1,000 topranked companies across the world. We analyze rank variations YoY for the top ten innovation rankers. We introduce for the first time the terms Innovation Power (inP) and Innovation Momentum (inM) to qualitatively describe rank trends and draw our conclusions on why variations are seen in these rankings and whether the trends have scope for predictability of future ranks. This implies there is clarity and consistency on the basis for which participants rank these companies.

\section{LITERATURE REVIEW}

Management and economics researchers who attempt to measure innovation classify innovation into technological and organizational innovation (Higgins, 1995). Organizational innovation is difficult to measure but easy to anecdotally describe. Technological innovation was always thought to be correlated to R\&D investments, number of patents filed and awarded, number of new products the company makes/markets, its revenue growth from new products, and market capitalization, for example. These variables are a few from a list of many popular ones that are standardized and used to measure technological innovation. Researchers tend to use these to measure technological innovation, implying that the higher the comparative value of these variables in samples (like companies, for example), the higher the technological innovation value. These measurements require ethnography, survey research designs, field studies, case study approaches, to name a few ways by which data are collected in measuring innovation. Internal and external validity of the researcher's methodology also 
impacts how innovation is ranked. When a large global sample of experts rank companies on innovation, the method potentially has higher external validity.

Not so commonly measured, though in the context of corporate innovation, are the terms business model or customer engagement innovations (Chesbrough, 2010). With changes in technology today, implying lowered cost of production and sales delivery from the current prevalence of internet and wireless technology, software-based tools, digitized data processing in executing customer service, the classification of marketing innovations is possibly underplayed in innovation measurement with research scholars. Indeed, we see a broad-based trend of software-driven innovation, where internet and mobile based solutions prevail in medical solutions, such as ICU management or genomics and drug design; or transportation management, e.g. driverless cars, accident prevention sensors and hybrid fuel efficiency; or data storage management and cloud computing; big data analytics and customer care, or drones to manage pests in agriculture. Across the board, there appears to be a movement towards big data and wireless technology-based solutions irrespective of the industry the company is classified in. This brings one to think that companies that are traditionally high on infrastructure investment doing business in what was traditionally called capital-intensive industry might be slower to adapt and change over to the information technology intensive face of innovation. They are slow, because it means a radical overhaul of their organization's processes, core competencies, management structure and even business model, in sum almost a company shut down. These companies may find themselves going lower on innovation rankings compared to counterparts that were aware of such changes and planned them in a phased manner, or compared to new entrants, i.e. start-ups, that embedded these IT capabilities into their core DNA from the start from the start. This includes using the internet infrastructure, social media and dynamically accessed virtual storage solutions to their ultimate capacity. Simply said, moving business operations towards software dominance over hardware dominance not only reduces cost, but also permits a modular, flexible and agile way of managing company performance. One wonders whether companies that were at their core software dominant have an advantage over those that were not. And, whether companies that traditionally had multiple industry focus find it difficult to change over to a software dominant focus across multi-sector businesses that they currently manage.

The next aspect we touch in the context of innovation measurement is whether the business model reaches a niche set of customers versus a large reach of customers. When companies reach larger bases of customers across regions, culture, and language barriers they become the darling of everyone's every day activity; Facebook is such an example. In contrast, this is not the case for Tesla, although both Facebook and Tesla are popular depending on who is asked the question. On the other hand, Google and Apple appear closer to Facebook on this aspect of measurement, i.e. reach. The degree to which a large customer base is reached tends to make the company a buzzword in everyone's mind thus creating the sensation it needs to rise in its public popularity, and an emotional value gets created. Emotionally engaging business models are interesting and a measurement construct for innovation of this classification may need to emerge in the innovation measurement repertoire. Interestingly, while wide reaching emotional engagement, via marketing and customer involvement, is critical for economic value, the emotional model works for narrower reach solutions too. Niche areas, for example, such as blood-based detection of cancer versus invasive biopsy, if achievable thanks to genomics, can become an emotionally accepted solution that evokes the same popularity as wide reach though in a much smaller set of customers.

Finally, with measurement, the use of various research designs such as survey research, ethnography, the Delphi method, for example, provides scope for limited conclusions, given the method. In survey research, the use of global expert rankers with the ranking method, which is not questionnaire-based, requires the use of experienced rankers who are experts on company performances to be able to rate companies on innovation. A homogeneous sample of global practicing experts in industry will rank global companies similarly. This research design may use two approaches, define innovation for the sample and ask them to rank against such a measurement construct or permit them to evolve their own experiential mental paradigm of innovation 
whilst they rank companies. Irrespective, when using homogenous samples, their ranking will have higher similarity than ranking from a heterogeneous mix of individuals who are non-industry (academic) and practicing executives in industry. Thus, while the measurement construct and variables to be chosen to measure innovation are still evolving, the method by which data are gathered also will have a bearing on the outcome that states which company is indeed innovative.

Today's innovation ranking agencies attempt to measure innovation using various approaches. The method that PWC Strategy\& uses as seen in their public documents is to ask a sample of experts to rank order companies globally year over year (Strategy\&, 2017). When doing this, we must keep in mind that rankers may rank a company from organizational, technological, economic, emotional, change management capability, software dominance, mass reach, public communication and such aspects of innovation whether as an input, throughput or output of innovation. Thus, when a practitioner executive expert is asked to rank global companies on innovation, it is difficult to elicit what mental paradigm is being used, but it is likely to be one or more of them. Based on the fact that the Strategy\& survey involved 1,000 senior executives from around the world, it is probably safe to assume that these participants were likely to adopt views mentioned here for their innovation ranking. From a methodological perspective, the only way to find out is to survey them directly. But this is impossible and beyond the scope of this paper. Another way to find out what happened is to compare multiple agency rankings to see if differences occurred and analyze why they may have occurred. In this approach, only assumptions of why there is a difference can be made. Yet, another approach is to assess whether financial performance variables, such as revenue growth, profit, and market capitalization, come out correlated to the global ranking of innovation. This was already done by Strategy\&.

To sum up this discussion of measurement of innovation, we state that our method uses secondary data from global rankings and dwells on detailed analysis of rankings in a manner to assess if these rankings hold inherent validity or were random measurements of innovation.

\section{METHODOLOGY}

Strategy\&, formerly known as Booz \& Company, is now a division of PricewaterhouseCoopers (PwC). $\mathrm{PwC}$ is said to have a network of firms in 157 countries. Strategy\& was initiated in 2014 by forming a separate and global consulting team of experts focused on: "strategy-through-execution under one roof" (Strategy\&, 2013). The studies conducted by this team analyze R\&D footprints and they evolved into what came to be called the Global Innovation 1000 study. These studies are widely claimed to be a comprehensive assessment of the relationship between $\mathrm{R} \& \mathrm{D}$ investments and corporate performance. The studies have shown that the success of companies is not in their R\&D spending figures, but more in how and where they spend their R\&D. The Strategy\& ranking on innovation is a good illustration of agency rankings. Strategy\& provides rankings of companies that achieved top 100 rankings chosen from a Global 1000. The overall sample is about 207 companies over 23 countries. These companies conduct R\&D in over 2,041 R\&D sites spread over 60 countries and representing about $71 \%$ of the Global 1000 . The experts ranking the companies are senior executives in the most successful corporations in the world (Jaruzelski, Schwarts, \& Staach, 2015).

The Strategy\& ranking data are used as background to this paper in order to understand variances in YoY rankings of global innovation within the agency Strategy\&. The methodology used by Strategy\&, as described by the company (Jaruzelski, Schwarts, \& Staach, 2015), was to ask global innovation executives from 1,000 companies about their companies' experiences with global innovation, as well as their views on successful innovation practice. The 369 respondents accounted collectively for more than USD 106 billion in R\&D spending, or about $16 \%$ of the total R\&D spending by all the 1000 companies. For the purpose of obtaining the Top-10 Innovation Ranking, each respondent was asked to rank the three (3) top innovative companies (Strategy\&, 2017). The companies ranked were obtained from a list of 2,011 companies spanning five geographic regions. It appears that each ranker, namely an executive, ranked the companies on innovation, according to their own personal mental paradigm of innovation. In this paper, we refer to this method as experiential ranking of innovation 
by industry experts. In such a method, the rankers are not provided with a definition of innovation to follow by the agency like Strategy\&. The experiences rankers had over the years in understanding industry growth trends, $\mathrm{R} \& \mathrm{D}$ footprints, company's financial performances and global economic growth must have conditioned their mental paradigm to rank what is innovative from what is not.

One major finding of the Strategy\& longitudinal study of the innovation ranking from 2010 through 2015 , and which lends support to the external validity and objectivity of the ranking, is that the top 10 innovators, as ranked by the executives, led the top $10 \mathrm{R} \& \mathrm{D}$ spenders on all three financial metrics, i.e. (i) revenue growth (5-yr CAGR), (ii) EBITDA as percent of revenue (5-yr average), and (iii) market capitalization growth (5-yr CAGR) for all the seven years in which the innovation ranking was conducted (Jaruzelski, Schwarts, \& Staach, 2015).

As stated earlier, our objective is to understand the variances in YoY ranks per company, and shed some insight on the consistency of such ranking, and hence our ability to use it to predict future ranking performance of those top 10 companies. Our methodology consists of three stages. The first is to study the ranks. We do this with various approaches. We collected the innovation ranking of the top 10 most innovative companies worldwide from 2010 through 2016 of the Strategy\& website (Strategy\&, 2017). We study year 2016 as the current picture of global innovation rankings to obtain an understanding of the current rank holders. We then examine the ranks over a period of seven years to study the change in ranks. We attempt to empirically categorize companies into high innovation ranks, consistency of ranking, those that emerged out of the blue (not present in years 2010, 2011), those that wavered or were inconsistent in their rankings, but held the top 10 positions, and those that appeared once or occasionally in the years 2010 to 2016 .

In order to define and extract quantitative metrics, we introduce a Normalized Innovation Rank (inR) of the top 10 innovators in such a way where a higher $i n R$ is better (e.g., in $R=10$ for Apple for ranking No. 1, and $i n R=9$ for Google for ranking No. 2). Any company that does not make it to the top 10 has a rank of 0 . This renormalization al- lows us to apply our longitudinal analysis even for companies that do not make the Top-10 ranking throughout the full 7 years of ranking as follows:

$$
\operatorname{inR}(y)=(\operatorname{Count} R-\operatorname{Rank}(y))+1,
$$

where CountR $=10$ (total number of companies that made the ranking), and for any company that didn't make the ranking in year $y$, i.e. $\operatorname{Rank}(y)>10$, then the inR $=0$.

To capture the qualitative difference among the top 10 innovators over the 7 years of ranking (2010-2016), we use inR to introduce the concept of the Innovation Power (inP) of an organization that allows it to maintain or even improve its innovativeness over a sustained time. We invert the ranks as in Eq. 1, and define inP for a particular year $y$ as follows:

$$
\operatorname{inP}(y)=\frac{\operatorname{inR}(y)-\operatorname{in} P(y-1)+1}{\text { Count } R-i n R(y)+1} .
$$

The numerator in equation 2 describes the ability of the company to maintain or improve its ranking from the previous year, so a positive numerator indicates a positive power, and the higher it is, the greater improvement in ranking it reflects. The denominator, on the other hand, describes the innovation power of the company relative to the other top 10 innovators. So, the higher the inR of a company, the lower the denominator, and hence the higher its innovation power relative to its peers. In sum, the Innovation Power of a company measures the relative ability of a company to maintain or improve its ranking relative to its peers. The higher the ranking of the company, the higher the Innovation Power it requires to maintain its ranking.

We then use the inR to study the YoY changes in rank for which we introduce the concept of Innovation Momentum (inM), simply defined as:

$$
\operatorname{inM}(y)=\operatorname{inR}(y)-\operatorname{inR}(y-1) .
$$

We then use inM to develop a predictive model of the inR for the following year and compare with the one obtained from the top 10 ranking, by calculating the correlation coefficients between the predicted and the actual ranking. We finally 
predict the inR for 2017 for the top 10 in 2016 and draw our conclusions about experiential ranking of innovation by industry experts.

We emphasize to the reader that our study is not of a statistical nature and hence neither our approach nor our conclusions depend on how many companies are being ranked. In other words, our study focuses on the top 10 innovators, but could be used just as well for the top 5 or the top 50 if that ranking were available. Also, the predictive ranking model we will be presenting below is reminiscent of a kinematic model that depends only on the historical innovation ranking of the company under consideration and is explicitly independent on the performance of the other nine companies included in the ranking. In other words, the value of the ranking predicted would not change if we had a much larger number of companies being ranked.

\section{RESULTS AND DISCUSSION}

\subsection{Strategy and ranks in the year 2016}

The companies that featured on the 2016 rank list were Apple, Google, 3M, Tesla Motors, Amazon, Samsung, Facebook, Microsoft, General Electric, and IBM. These are all large, global and stable companies with headquarters in USA (9 companies), and South Korea (1 company). This list of rankers clearly puts USA in the position of leadership with innovation, and surprisingly there is no presence of Europe, or Japan, with Japan's Toyota dropping out in 2016 after it made the No. 10 spot in 2015.

Table 1. The 2016 Innovation Ranking by Strategy\&

\begin{tabular}{c|c|c} 
& & Source: Strategy\& (2017). \\
\hline Company & Innovation rank & Country \\
\hline Apple & 1 & USA \\
\hline Google & 2 & USA \\
\hline $3 M$ & 3 & USA \\
\hline Tesla Motors & 4 & USA \\
\hdashline Amazon & 5 & USA \\
\hline Samsung & 6 & South Korea \\
\hline Facebook & 7 & USA \\
\hline Microsoft & 8 & USA \\
\hline General Electric & 9 & USA \\
\hline IBM & 10 & USA \\
\hline
\end{tabular}

Insights on 2016 rank positioning: Using an impressionist's approach with the data, we see that another point about these top innovators is that all of them are over fourteen years of age, the youngest being Tesla Motors.

Insights on the rank leaders: Apple and Google are consistently viewed to be successful and innovative companies, although they are very different in many ways. Generically speaking, both are from the ICT industry domain. The historical success of Apple is with their stylish product design, user-friendly operating system and its applications, now universally available across multiple user interface devices, like the PC, laptop, iPAD, and mobile phone. They clearly have a double-edged success both on the software and hardware side. However, making their software work intuitively across all of the hardware devices a typical consumer uses in day-to-day life, irrespective of age, gender, culture, language and geography, helps them proliferate and thus capture the number One position as globally innovative. Google clearly comes from a different ICT sector, that of search science, which is commercialized through its advertising revenues, representing nearly $90 \%$ of its total business model (ref: R\&P, "How Google Makes Money", https:// revenuesandprofits.com/how-google-makes-money/). Should Google start realizing significant revenues from its mobile operating system, applications, software and hardware devices, something it has so far consistently failed to achieve despite its best attempts, e.g. Google Glass, then it might be able to rise to rank 1. However, its core competency, being what it is, helped it drill down into consumer-information-search-behavioral-science, which is rare and much needed given the aggressively galloping need for authenticated information to understand markets and complex phenomena today. Google, despite not having what Apple has, stands second in rank undisputed since 2010 and onward. It rises to this level of rank, we assume, because again, like Apple, it deals with a typical consumer's daily life, irrespective of age, gender, culture, language and geography. It's not unusual for consumers to start and end their day with Google.

It is well known that control over the operating system gives companies an edge in the software industry; the leadership of Microsoft in the computer industry is a good example. 
Insights of Microsoft's lower rank: Microsoft has the $8^{\text {th }}$ rank. The difference being that Microsoft, unlike Apple, has only a software advantage and no ownership over hardware devices. Hence, unlike Apple that has the power to fully control the consumer's experience through both its software and hardware operations, Microsoft is dependent on other device providers and this collaboration may have dropped its rank to the $8^{\text {th }}$ ranker. On the other hand, it's not like all the device hardware and software experts rank high.

Insights on device and software owner's ranks: Samsung who holds ownership over hardware and some superficial level over the operating systems related only to the Google-owned mobile system, e.g. Android, fell from $4^{\text {th }}$ in 2015 to $6^{\text {th }}$ in 2016 . The onset of Samsung into this software/hardware space is much later than that of Microsoft that started with the PC much earlier. Yet, Samsung has taken over Microsoft in rankings, but neither are anywhere close to Apple that holds rank 1.

The experiential rankings the executives might have used are difficult to interpret in the context of Apple, Microsoft and Samsung. These three, we feel, were somewhere common to each other in their technology, products and business success. This analysis will become clearer when we look at other factors that might have influenced this ranking.

Facebook's rise in ranks: Staying in the same space of companies that grab the morning and the night of a consumer, another such example is Facebook, which has managed to rise to rank 7 in 2016 . Facebook again has the character of addressing consumers, irrespective of age, gender, culture, language and geography. There may be a reason why they are not seen in year 2015. Facebook addresses the social needs of consumers, but Google addresses a larger need of information access by that same consumer. Thus, the nature of service that Google provides to the consumer helps capture them far more than will Facebook. Chances of Facebook getting into operating systems, applications and devices is bleak unless through collaboration, which again has its challenges. Besides, if Facebook tries to use the follower strategy, since the life cycle of this business area is already tried by others mentioned here, trailing behind the giants will be un- wise, thus they will likely remain with addressing social needs. McClelland (1987) made it clear that humans want power, affiliation and belongingness and Facebook successfully addresses this using the internet to manifest these human needs. Those high on belongingness and gain of power for the same might be active users of Facebook. Facebook does also provide those with shy personality traits an avenue to belong and feel power as social media technology nurtures this anonymity. However, the users of Google are from all classifications or strata of customer populations. These include those whose needs that McClelland mentions are served. Google potentially covers all ages, genders, cultures; languages and geographies, including needs, personality and attitudes of users, thus giving Google the edge it wants over other companies if it strategizes this reach right.

Ranks of erstwhile leaders, 3M, GE, IBM: Three other companies in the top ten ranking are worthy of getting clubbed together for certain reasons, these are $3 \mathrm{M}\left(3^{\text {rd }}\right)$, General Electric $\left(9^{\text {th }}\right)$, and IBM $\left(10^{\text {th }}\right)$. While IBM did belong more to the companies mentioned in the above paragraphs, their ICT applications spread across areas that $3 \mathrm{M}$ and General Electric also cover. $3 \mathrm{M}$ and General Electric are more similar to each other than is IBM. What is common is their age, size, international presence and, simply put, might. While there are products that are end-user consumer based (Business-toConsumer) many of the products that all three of them produce are also B2B (Business-to-Business). This puts them away from the apparent character of Google and Facebook, serving every typical consumer's day-to-day life visibly, morning and evening, irrespective of age, gender, culture, language and geography. So much so the executives who ranked them ranked them much lower than companies what address end-user consumer (like Apple and Google) in a B2C manner. 3M, however, shows a higher rating than GE and IBM.

In light of the innovation focus of these three companies 3M, GE and IBM, one wonders why they are ranked much lower? Are they perceived to be companies of the past although they have currency? Are the executives wrong in perceiving Apple and Google as more innovative than IBM, $3 \mathrm{M}$ and General Electric? We leave this open for others to interpret. 
Normalized performance of industry peers

1

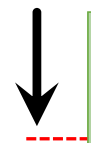

Lowest possible score: 0
63

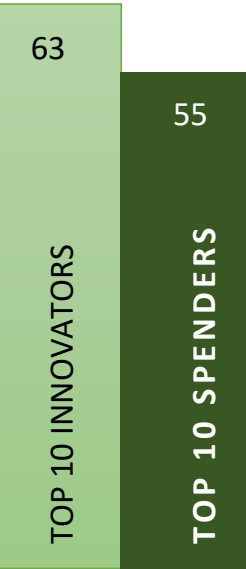

Revenue growth 5-yr. CAGR

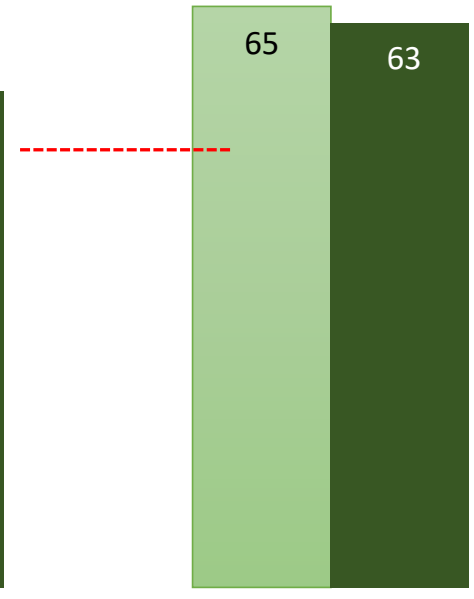

EBITDA as \% of revenue 5-yr. Avg.
Source: Jaruzelski, Schwarts, and Staach (2015)

Figure 1. Normalized performance of top 10 innovators versus top 10 R\&D spenders, showing, on an indexed basis, the innovators consistently outperforming the spenders on all 3 most important financial metrics

Amazon's rank the emerging leader insights: Amazon's ranking is an interesting case. One wonders whether Amazon $\left(5^{\text {th }}\right)$ got its ranking for its e-commerce or its emerging leadership with cloud computing, and other innovations such as the Kindle, and more recently Alexa and Echo Dot? While its e-commerce business shows the character of addressing the typical consumer's day-today life, irrespective of age, gender, culture, language and geography, this may be the case when consumers access their e-commerce website from any device or operating system, where a browser will take them to Amazon's online shops, it's well known that only a partial lot of the world's population uses this, unlike the use of Google's service. Amazon not only falls in the ICT category of industry, but also covers the sourcing, inventory, logistics and supply chain industry. This part of Amazon is truly B2C. However, their leadership in cloud services and computing services, thought currently $\mathrm{B} 2 \mathrm{~B}$, possibly has potential scope of moving to $\mathrm{B} 2 \mathrm{C}$, which means their climb to higher innovation rankings is probable in later years.

Tesla's ascent despite a younger age: It is interesting that Tesla gets into the top ten although it's relatively younger and in a niche and new industry of electric cars, and so far with a relatively limited market reach. It's possible that the unique com- bination of design appeal, green technology and driving power into its cars has raised Tesla to well above its peers within the century old automotive industry. Tesla stands fourth in rank next only to Apple, Google and 3M, this last one moving up 3 spots from 2015, and taking the No. 3 spot away from Tesla.

So, this dark horse, which is strange to fit in anywhere, which is not at all yet serving the typical consumer in their day-to-day life, irrespective of age, gender, culture, language and geographical, baffles everyone with a fourth rank; and we do mean Tesla Motors. Despite playing in the tiny niche market of overpriced electric cars, this company has managed to capture the admiration and the interest of thousands of fans and investors. Still unprofitable, and in fact the only top 10 innovator having negative profits, Tesla has gained a market capitalization that has recently exceeded that of Ford and GM, making it the most valuable car company in America as of April 10, 2017. Tesla makes us wonder whether it's the unique features of its cars, or instead the sustainability values this company brings to the environment and their disruption potential on the car industry that makes it a sudden darling of rankers. The fact that a relatively tiny and unprofitable car company rises to third rank in 
Table 2. The rank (Rank), the normalized Rank (inR) and the Innovation Power (inP)

\begin{tabular}{|c|c|c|c|c|c|c|c|c|c|c|c|c|c|c|c|c|c|c|c|c|}
\hline \multirow{2}{*}{ Company } & \multicolumn{3}{|c|}{2016} & \multicolumn{3}{|c|}{2015} & \multicolumn{3}{|c|}{2014} & \multicolumn{3}{|c|}{2013} & \multicolumn{3}{|c|}{2012} & \multicolumn{3}{|c|}{2011} & \multicolumn{2}{|c|}{2010} \\
\hline & $\overline{\operatorname{Rank}}$ & inR & $\ln P$ & Rank & in $R$ & $\ln P$ & Rank & inR & $\ln P$ & Rank & in $R$ & $\ln P$ & Rank & inR & $\ln P$ & Rank & $\operatorname{inR}$ & $\operatorname{In} P$ & Rank & inR \\
\hline Apple & 1 & 10 & 10 & 1 & 10 & 10 & 1 & 10 & 10 & 1 & 10 & 10 & 1 & 10 & 10 & 1 & 10 & 10 & 1 & 10 \\
\hline Google & 2 & 9 & 5 & 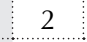 & 9 & 5 & 2 & 9 & 5 & 2 & 9 & 5 & 2 & 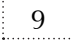 & 5 & 2 & 9 & 5 & 2 & 9 \\
\hline Amazon & $\ldots$ & 6 & 2 & ? & 6 & (2) & . & 8 & $\ldots$ & 4 & $\ldots$ & 18 & 10 & 1 & 2 & 11 & 0 & 1 & 11 & 0 \\
\hline Samsung & 6 & 5 & (2) & 4 & 7 & 3 & 4 & 7 & 0 & 3 & 8 & 7 & 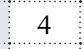 & 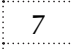 & 10 & 7 & 4 & 4 & 9 & 2 \\
\hline & 4 & 7 & 0 & 3 & 8 & 10 & 5 & 6 & 10 & 9 & 2 & 3 & 11 & 0 & 1 & 11 & 0 & 1 & 11 & 0 \\
\hline $3 M$ & 3 & 0 & 13 & 0 & 5 & 2 & 0 & ? & 0 & s & 6 & (2) & ‥ & 8 & 3 & 3 & 8 & 3 & 3 & 8 \\
\hline & 9 & 2 & (1 & 7 & 4 & 1 & 7 & 4 & 0 & 6 & 5 & 0 & 5 & 6 & 0 & 4 & 7 & 3 & 4 & 7 \\
\hline Microsoft & 8 & 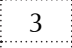 & $\cdots$ & 8 & 3 & $\ldots$ & $\ldots$ & 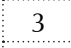 & 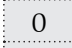 & 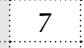 & $\cdots$ & $\ldots$ & $\ldots$ & 5 & & 5 & 6 & 4 & 6 & 5 \\
\hline $\mathrm{IBM}$ & 10 & 1 & 0 & a & $\ldots$ & 1 & 9 & 2 & 0 & 8 & 3 & 2 & 9 & 2 & (2) & $\ldots$. & 5 & 5 & 8 & 3 \\
\hline & 11 & 0 & 1 & 11 & 0 & 0 & 10 & 1 & 2 & 11 & 0 & (2) & 8 & 3 & 1 & 8 & 3 & 0 & 7 & 4 \\
\hline Toyota & . & . & . & (2) & 1 & 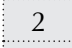 & 'ד & 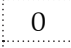 & 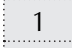 & 吸 & 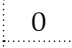 & (3) & 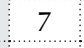 & $\ldots$ & $\ldots$ & 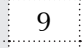 & 2 & (3) & $?$ & 6 \\
\hline Facebook & 7 & 4 & 7 & 11 & 0 & 1 & 11 & 0 & 0 & 10 & 1 & 2 & 11 & 0 & 0 & 10 & 1 & 2 & 11 & 0 \\
\hline
\end{tabular}

Notes: 1 . Rank, in $R$ and in $P$ of each of the companies made the top 10 ranking over the seven years of survey. 2 . The inP allows for negative values, which are shown in parentheses, using conventional accounting format, for ease of reading.

2015 speaks well for the executives that ranked it and society's movement into a healthier world. Having stated this, there are many companies that promote a greener form of commerce, yet none of them have entered the top 10 ranks. The only other vehicle company in the top 10 ranks is Toyota. Toyota is much older than Tesla and focuses on areas similar to Tesla. The only difference being that Tesla's core strength is electric cars and energy storage, while Toyota has a wider range of focus in vehicles. It is notable that the older Toyota got ranked much lower than younger Tesla by the rankers.

Notwithstanding all the above qualitative observations, a key objective finding is that although the Innovation Ranking is an opinion-based average and does not repose on any clear factual or quantitative metric, as the R\&D spending does, it remains undeniable that the top 10 innovative companies outperformed the top $10 \mathrm{R} \& \mathrm{D}$ spenders on all the key financial indicators, such as revenue growth, EBITDA as a percentage of revenue, and market cap growth (see Figure 1) (Jaruzelski, Schwarts, \& Staach, 2015). This observation alone lends significant credence to this ranking, and leads us in the next sections of this article to not only question the conventional metrics of innovation, such as R\&D spending, but also to explore a new and semi-empirical model of innovation, which is based on the Strategy\& Innovation Ranking data.

\subsection{Innovation power}

If the top ten companies were the same ones YoY, the total sample of companies being analyzed in this paper should have been 10 . However, there were 13 companies in total entering the top ten ranks in the last seven years. We take a closer look at rank changes from the perspective of those with high innovation ranks, consistency of rank, those that emerged out of the blue (not present in years 2010,2011 ), those that wavered and were inconsistent in their rankings, but held the top 10 positions, and those that appeared once or occasionally, and dropped out later. We also look at those with positive and negative innovation power.

The picture provided over seven years shows variances only from rank 3 and downward. In other words, the first two ranks were consistently and remarkably held by Apple and Google, respectively, over the seven years. The reason for Apple and Google consistently holding the first and second ranks over a seven-year period reinforces the high external validity of innovation ratings by the executives for these two companies.

Using the definition of Normalized Ranking $\left(\operatorname{In} R \_n\right)$ and Innovation Power $(\operatorname{In} P)$ in equations 1 and 2, respectively, we show in Table 2 the values of inR, inR_ $n$ and inP for each of the 12 companies excluding Intel that made the top 10 innovators over the 7-year period of the survey from 2010 to 2016. 
From Table 2, we categorize the companies as follows: Apple and Google are high innovation rankers that are also consistent. Tesla Motors emerged out of the blue in year 2013 and was not on the rank list between 2010 and 2012 . Amazon also shows the character of emerging out of the blue as they were not seen in the rank list between 2010 and 2011. Both Tesla and Amazon significantly improved their ranking over the years. Many companies wavered between third and tenth ranks in the top ten ranks over the seven years. These companies were Samsung, IBM, General Electric, 3M and Microsoft. Whilst these companies were inconsistent and increased or decreased in ranks, they held on to their top 10 positions. Four companies appeared occasionally or once. The ones that made occasional appearance were Toyota, Procter \& Gamble and Facebook, and the one that made only one appearance was Intel. Of these four, Toyota and Procter \& Gamble started at a healthy ranking in 2010, but got consistently worse until they both dropped out, while Facebook seems to have started at the bottom of the ranking initially and significantly improved in 2016. Intel barely made the ranking in 2010 and to never reappear again. This is the picture as seen from raw ranks.

To explain this further, we use the newly introduced term of "innovation power" of an organization, as defined in equation 2 above, to mean the degree to which a company is able to hold onto its rank without a change over the seven-year period. In Figure 2 below, we show the 3-year average of the Innovation Power (in $P$ ) of all the 12 companies from 2013 to 2016 (after dropping Intel which made it to the top 10 only once in 2010), which is calculated by averaging inP over the last trailing years. For example, the average Innovation Power for the year 2013 would be calculated as:

$$
\begin{aligned}
& A v g_{-} i n P(2013)= \\
& =\frac{i n P(2013)+i n P(2012)+i n P(2011)}{3} .
\end{aligned}
$$

Since the earliest Innovation Power available is in 2011, the earliest 3-year Average Innovation Power that we can calculate is in 2013 and onward. Figure 2 below shows the plot of 3 -year average of the Innovation Power for the top 10 innovators.

Innovation Power of the top 10 innovators (3-year average)

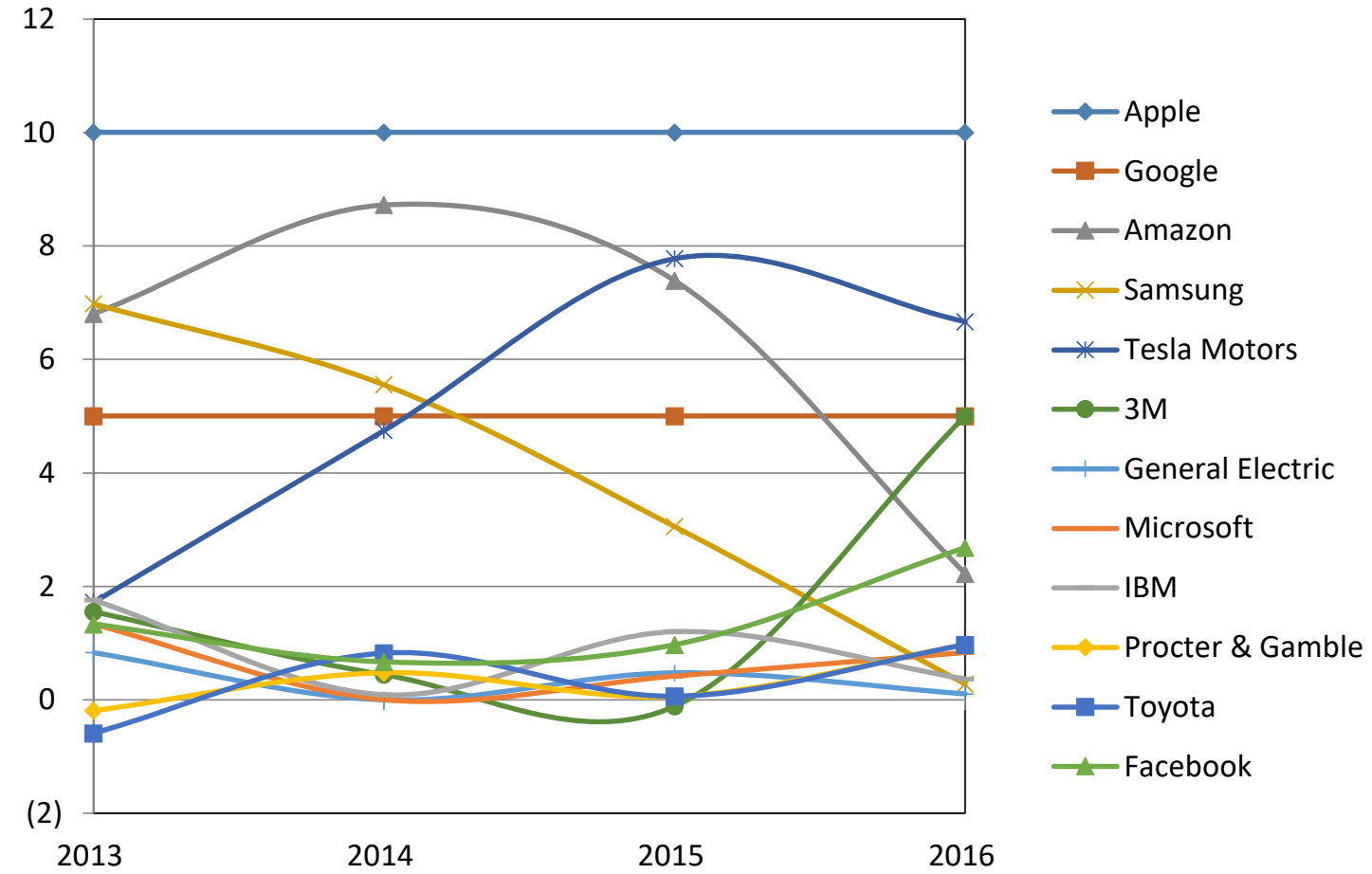

Figure 2. The 3-year running average of the Innovation Power of each of the top 12 innovators over the four-year period from 2013 through 2016 


\subsection{Qualitative clusters developed based on inP:}

Ideally, we would have used the rank order cluster analysis, however, since the data are small and appropriate non-parametric statistics is unavailable to use, we stick to our qualitative insights in clustering these companies using our evolved concept of inP. Figure 2 reveals some interesting and distinguishing features of the top 12 innovators over the total of seven years. The top 12 essentially fall in 4 smaller groups.

Group 1: Constant Top Innovators (CTI) - There are only two companies in this category, and those are Apple and Google, maintaining an inP of 10 and 5 , respectively, over the whole period of their ranking.

Group 2: Constant Bottom Innovators (CBI) There are five tightly packed companies in this category, namely GE, Microsoft, IBM, Procter \& Gamble and Toyota. They all oscillate between an in $P$ of 0 and 2, markedly lower in their Innovation Power compared to Group 1, and unable to challenge the top 2 Group 1 innovators.

Group 3: Declining Innovators (DI) - There are two interesting companies that fall into this category, and those are Amazon and Samsung. Both companies rose in their Innovation Power above Google, with Amazon even approaching Apple, only to see their Innovation Power steadily and rapidly decline towards the CBI level in 2016. Clearly, these two companies have shown some tremendous innovation in the recent past, but now seem to be struggling to maintain that streak.

Group 4: Rising Innovators (RI) - This is perhaps the most fascinating category and the one to watch the most closely, and this includes three companies, namely Tesla, $3 \mathrm{M}$ and Facebook.

\subsubsection{Insights on the rising innovators}

It is worth making additional observations about the RI group. Despite its initial niche market of electric vehicles, Tesla is emerging as a much more ambitious and disruptive player in the automotive industry, and even beyond. A closer look at the company reveals the vast extent of that po- tential disruption. Besides the commitment to electric cars only, the company is also leading in cutting-edge technology in the industry such as autonomous driving, safety and security, software capabilities, remote software upgrades and security patches and overall quality features. Indeed, in 2016, the Tesla Model S was rated for the second time in a row as the highest quality vehicle in the entire industry by Strategic Vision (Miller, 2017). "To be able to fix problems and add features through a software download overnight instead of a trip to the dealer is a powerful tool. In many cases, it actually enhances their confidence in the product more than if the problem had never existed in the first place". Another innovative, and equally disruptive, aspect of Tesla is its business model. Tesla is the first car company in history that chose to do away with a dealers network and instead sell its cars directly to the consumer. Borrowing a page from Dell Computers, Tesla is able through this model to keep all its product margin to itself, hold a very small inventory of cars, offer a higher level of customization to the consumer and finally get paid before it has to pay its suppliers. Finally, armed with such powerful technical features and advantageous business model, as well as the largest Lithium-based battery factory in the world, the company is determined to enter the much larger automotive mass market with the lower priced Model M. All of the above positions Tesla favorably in maintaining a high in $P$ and hence maintaining a higher ranking.

The second highest in inP among the RI group is $3 \mathrm{M}$. Breaking away from the CBI group in 2015, 3M's spectacular rise in inP above Google in 2016 warrants some further analysis. Govindarajan and Srinivas describe the $3 \mathrm{M}$ Innovation Mindset in Action, where $3 \mathrm{M}$ employees (i) see and act on opportunities, (ii) use "and" thinking to resolve tough dilemmas, (iii) use their resourcefulness to break through hurdles, and (iv) maintain a laser focus on outcomes. This success in embedding innovation into the fabric of the company at $3 \mathrm{M}$ is clearly the driver of the company's in $P$ and its ability to constantly renew itself through innovation. This capability is also clearly reflected in its financial results. Indeed, over a 20 -year period, $3 \mathrm{M}$ 's gross margin averaged $51 \%$ and the company's return on assets averaged 29\% (Govindarajan \& Srinivas, 2015). 
Finally, the third RI member is Facebook. Founded by Mark Zuckerberger in 2004, at about the same time as Tesla, Facebook has quickly risen to a global profitable behemoth of almost USD 400 billion in market capitalization (as of March 8, 2017). With little intellectual property (IP) to speak of, Facebook has been able to capture the lion's share of social media advertising market amounting to an estimated USD 22.37 billion of the global USD 32.9 billion market (Statista, 2017). This performance once more underpins the increasing evidence that innovation, while impacting strongly financial performance, has little bearing with R\&D spending or intellectual property in the traditional sense of patents. Facebook has grown in its rank more because of service innovations to meet its consumers' needs, thus having an engaged advertising revenue.

\subsubsection{Insights on software vs hardware emerging from inP}

Another general and important observation that Figure 2 affords us to make is that with the exception of $3 \mathrm{M}$ and Microsoft, one key distinguishing difference between the high-ranking and high-emerging and low-ranking top 12 innovators is that the former have a very high software competency (Apple, Google, Amazon, Tesla, and Facebook), while the latter tend to be more hardware-focused (GE, IBM, P\&G, Samsung, and Toyota). This suggests once more that software-driven innovation has taken over from hardware-driven innovation, providing further credence as to why patents, which tend to be predominantly hardware-focused, have become a lot less important in driving innovation, although, to some extent, a volume of software patents is also seen.

\subsection{Prediction of future ranking}

Even though it is perception-based, the Strategy\& Innovation Ranking seems to empirically reflect a significant level of external validity, at least in its ability to show a relatively stronger correlation with the key indicators of financial performance than R\&D spending, as shown in Figure 1. Yet, the critical reader may still be sceptical as to whether this ranking has any inherent consistency and objectivity, or whether instead it's completely subjective and random. To partially answer this question, we explore in this section the possibility of developing a somewhat predictive model of Innovation Ranking of the top 12 innovators, which is based on their prior ranking. The underlying premise is that if the ranking is totally subjective and random, then the predictive power of any model would be very low, while a high predictive power would be an indication of a significant level of inherent consistency and objectivity in previous rank assignments. In other words, although the ranks are perceptive, there is a consistent trend in the ranking and thus they are objective.

We remind the reader here of the concept of the Innovation Momentum (inM) in terms of the normalized innovation rank, as defined in equation 3 , in the methodology section of this paper:

$$
\operatorname{inM}(y)=\operatorname{inR}(y)-\operatorname{inR}(y-1) .
$$

Applying the formula to the following year, we write the inR for year $(y+1)$ as:

$$
\operatorname{inR}(y+1)=\operatorname{inR}(y)+\operatorname{inM}(y) \cdot 1
$$

where equation 3 states that the Innovation Ranking in the following year is equal to the Innovation Ranking in the current year plus the Innovation Momentum times the lapse of time of 1 year. This is the simplest form of a linear model that assumes that the innovation momentum of the company is somewhat constant during the whole one year. Note also that this model is not statistical in nature and hence is not affected in any way by the number of companies being considered for the ranking, whether it's 10 or 50 or 1,000 . It's purely "kinematic" in the sense that it depends uniquely on its previous innovation rank and its Innovation Momentum in the previous year. This is a key distinction and one that in fact allows two or more companies to have the same innovation rank value as will be shown below.

For illustrative purposes, we show in Table 3 the results of our model for predicted versus actual innovation ranking (normalized) for years 2014-2015, with the corresponding Innovation Momentum in $M$, computed using equation 3 above, and the values of in $P$ for each year, provided in Table 2 for the year 2014. Using equation 4, we then show the 
predicted value of the Innovation Ranking in $R$ for 2015 (2015 - inR (predicted)) and compare it with the actual Innovation Ranking for that same year as collected by Strategy\& (2015-inR (actual)). While we note that the model is unable to exactly pinpoint the ranking of each company, the variance is 1 or 0 for nine of the twelve companies, and is 2 for only two companies, namely Procter \& Gamble and Tesla, and 3 for Amazon alone. The overall coefficient of correlation between the predicted and actual values is $93 \%$. Perhaps most importantly, the model predicts precisely all the four innovation clusters.

Table 3. Predicted versus actual values of normalized Innovation Ranking for the top 12 innovators for 2015 based on 2014 ranking

\begin{tabular}{|c|c|c|c|c|}
\hline \multirow[b]{2}{*}{ Company } & \multicolumn{4}{|c|}{2014} \\
\hline & in $R$ & in $M$ & $\begin{array}{c}2015-i n R \\
\text { (predicted) }\end{array}$ & $\underset{\text { (actual) }}{2015-\text { inR }}$ \\
\hline Apple & 10 & 0.00 & 10 & 10 \\
\hline Google & 9 & 0.00 & 9 & 9 \\
\hline Amazon & 8 & 1.00 & 9 & 6 \\
\hline Samsung & 7 & (1.00) & 6 & 7 \\
\hline $\begin{array}{l}\text { Tesla } \\
\text { Motors }\end{array}$ & 6 & 4.00 & 10 & 8 \\
\hline $3 M$ & 5 & (1.00) & 4 & 5 \\
\hline $\begin{array}{l}\text { General } \\
\text { Electric }\end{array}$ & 4 & (1.00) & 3 & 4 \\
\hline Microsoft & 3 & (1.00) & 2 & 3 \\
\hline IBM & 2 & (1.00) & 1 & 2 \\
\hline $\begin{array}{l}\text { Procter \& } \\
\text { Gamble }\end{array}$ & 1 & 1.00 & 2 & 0 \\
\hline Toyota & 0 & 0.00 & 0 & 1 \\
\hline Facebook & 0 & (1.00) & 0 & 0 \\
\hline CorrCoef & - & - & - & 0.93 \\
\hline
\end{tabular}

Next, we summarize in Table 4 the same procedure we did for 2014 by simply showing the correlation coefficients we obtained between the predicted and the actual Innovation Rankings for the years 2012 through 2016. Since the model requires two previous years rankings in order to predict the following year's ranking, the earliest year we can use the model for is 2012 . We remind the reader that a normalized Innovation Ranking of 0 means that the company had dropped out of the top 10 list.
Table 4. Correlation coefficient between the predicted versus actual normalized Innovation Ranking of the top innovators for the period 2012-2016

\begin{tabular}{c|c}
\hline Year & $\begin{array}{c}\text { Correlation coefficient } \\
\text { (predicted versus actual) }\end{array}$ \\
\hline 2012 & 0.82 \\
\hline 2013 & 0.70 \\
\hline 2014 & 0.93 \\
\hline 2015 & 0.93 \\
\hline 2016 & 0.82 \\
\hline
\end{tabular}

As can be noted, with the exception of the year 2013, the model shows a correlation coefficient with the actual ranking of $80 \%$ or better for all the other 4 years. Finally, we use the model to predict the Innovation Ranking for the same 12 companies for 2017. We find the following ranking:

Table 5. Predicted normalized Innovation Ranking for the top 12 innovators in 2017

\begin{tabular}{|c|c|c|c|}
\hline \multirow[b]{2}{*}{ Company } & \multicolumn{3}{|c|}{2016} \\
\hline & in $R$ & in $M$ & $\underset{\text { (predicted) }}{2017-i n R}$ \\
\hline Apple & 10 & 0.00 & 10 \\
\hline Google & 9 & 0.00 & 9 \\
\hline Amazon & 6 & 0.00 & 6 \\
\hline Samsung & 5 & $(2.00)$ & 3 \\
\hline Tesla Motors & 7 & $(1.00)$ & 6 \\
\hline $3 \mathrm{M}$ & 8 & 3.00 & 10 \\
\hline $\begin{array}{l}\text { General } \\
\text { Electric }\end{array}$ & 2 & $(2.00)$ & 0 \\
\hline Microsoft & 3 & 0.00 & 3 \\
\hline IBM & 1 & $(1.00)$ & 0 \\
\hline $\begin{array}{l}\text { Procter \& } \\
\text { Gamble }\end{array}$ & 0 & 0.00 & 0 \\
\hline Toyota & 0 & $(1.00)$ & 0 \\
\hline Facebook & 4 & 4.00 & 8 \\
\hline
\end{tabular}

Table 5 makes several notable predictions, namely that several of the Constant Bottom Innovators, namely GE, IBM, P\&G and Toyota will totally drop out of the top 10 list or will at best be at the very bottom of the list if no new entrant threatens them. On the other end of the spectrum, the model also predicts that both $3 \mathrm{M}$ and Facebook will rise to the top with $3 \mathrm{M}$ vying for the top spot, and Facebook coming just below Google. Finally, the model also predicts that Tesla will maintain its high rank, while Amazon will reverse its decline of 2016 and threaten Tesla for the rank of 6 spot. 


\subsection{Limitations of results}

We used the rankings of Strategy\& to analyze their top ten innovation ranks. We are aware that the small sample size of 10 rank holders has limitations for interpretation and inferences, although these are a subset of a very large sample of global companies executives ranked them from. We are also aware that other agencies rank innovation, but have not used them in our analysis.
As far as our predictive model, the model relies solely on past performance, and hence is purely technical. As such, it takes no account of any fundamental changes in the market fortunes that might affect the companies' fortunes in any given year, and hence affect their innovation ranking. Also, the model allows two companies or more to tie for the same ranking, while this is not allowed in the Strategy\& ranking method, which will introduce additional variance between the ranks predicted and the ones actually achieved.

\section{CONCLUSION}

In this paper, we attempted to understand the rankings provided by expert rankers of the Strategy\& study with the intention to understand how these ranks may be arrived at in a homogenous sample of rankers. We find that there is consistency in the rankers' mental paradigm over time. We have analyzed variations in innovation rankings of Strategy\& for the past 7 years and introduced the concept of Innovation Power to help further categorize the top innovators into four different empirical clusters. The 3-year average of the Innovation Power for those companies shows that Apple and Google are packed together at the top of the innovation scale, while IBM, Microsoft, Procter \& Gamble, Toyota and General Electric are packed together at the bottom of that scale. In between, we have the risers such as Tesla, $3 \mathrm{M}$ and Facebook and the decliners such as Amazon and Samsung. Furthermore, we introduce the concept of Innovation Momentum and offer a very simple linear model to predict the normalized innovation rank of the top 10 innovators. We find a correlation coefficient that ranges from $70 \%$ to $93 \%$. More interestingly, the model is able to predict the innovation rank of 10 out of the top 12 innovators with a variance of 2 ranks or less and predicts precisely the various innovation clusters.

Finally, we predict the Innovation Ranking of the 2017 top innovators. Our results suggest that while Apple and Google will maintain their top spots, 3M, Facebook, Tesla and Amazon will vie for the top spots in that order, while General Electric, IBM, Procter \& Gamble and Toyota will remain in the bottom band of innovators.

We hope that this paper will instill the need for more appropriate definition and measurement design in the context of innovation perspectives given the rapidly changing organization design, production and sales delivery operations in business today. We acknowledge that our analysis is limited to large companies yet should offer valuable management perspectives that leaders and consultants need to delve upon given the wide need to remain innovative in currently changing markets.

We hope that the methodology used and presented here can find further application and refinement by researchers, students and consultants.

Contribution to innovation literature: Although our analysis and qualitative insights are primarily meaningful to corporate officers who are trying to increase their competitiveness through a better understanding of innovation, as well as to investors who are trying to identify the future top innovators, we feel that there is a contribution to academic literature on innovation as well. The contributions are in terms of innovation definition and measurement given that rankers use their paradigm when ranking companies. There is a dire need to revisit innovation definitions by scholars given the way technology and business are changing today. For example, innovation definitions are generic and do not consider the software versus hardware angle of why innovation may be ranked higher in magnitude. Correlating 
innovation with overall business performance indicators is essential over and above just patents and $\mathrm{R} \& \mathrm{D}$, albeit patents and $\mathrm{R} \& \mathrm{D}$ are still important for technology companies to grow their business. Innovation definitions do not consider emerging industry areas such as Facebooks social media industry or Amazon's e-commerce industry or Tesla's electric car industry. While we are not advocating that the definition of innovation be industry-specific given the fact that products go across industries today, the complexity of products and services using multiple industry disciplines appears to be forcing rankers who participate in such rankings to look at business performance indicators to decide their ranks rather than just newness, magnitude of innovation, $R \& D$ figures and $R \& D$ outputs.

\section{ACKNOWLEDGEMENTS}

The corresponding author is grateful to McMaster Universtiy for the research grant No. 5-55050 without which this paper would not have been possible.

\section{REFERENCES}

1. Archibugi, D., \& Iammarino, S. (2002). The globalization of technological innovation: definition and evidence. Review of International Political Economy, 9(1), 98-122. Retrieved from https://www.jstor.org/ stable/4177414?seq=1\#page_scan_ tab_contents

2. Baregheh, A., Rowley, J., \& Sambrook, S. (2009). Towards a multidisciplinary definition of innovation. Management Decision, 47(8), 1323-1339. https://doi. org/10.1108/00251740910984578

3. Bottazzi, L. \&. (2007). The International Dynamics of R\&D and Innovation in the Long Run and in The Short Run. The Economic Journal, 117(518), 486-511. https://doi.org/10.1111/ j.1468-0297.2007.02027.x

4. Burns, T., \& Stalker, G. (1961). The management of innovation. Retrieved from http://www. worldcat.org/title/managementof-innovation/oclc/228964

5. Chesbrough, H. (2010). Business Model Innovation: Opportunities and Barriers. Long Range Planning, 43(2-3), 354-363. https://doi. org/10.1016/j.lrp.2009.07.010

6. Damanpour, F. (1991). Organizational innovation: A meta-analysis of effects of determinants and moderators. Academy of Management Journal, 34(3), 555-590. Retrieved from https://www.jstor.org/ stable/256406?seq=1\#page_scan_ tab_contents

7. Edwards, A., \& Chaney, C (2016, June). Strategic Vision. Retrieved from https://www.businesswire. com/news/home/20160616005364/ en/\%E2\%80\%9CAmerican-QualityGreat-Again\%21-Domestic-Vehicles-Win

8. Ettlie, J. E., \& Reza, E. M. (1992). Organizational integration and process innovation. Academy of Management Journal, 35(4), 795-827.

9. Eurostat OECD (2005). Oslo Manual. Guidelines for Collecting and Interpreting Innovation Data.

10. Garcia, R., \& Calantone, R. (2002). A critical look at technological innovation typology and innovativeness terminology: a literature review. Journal of Product Innovation Management, 19(2), 110-132. https://doi. org/10.1111/1540-5885.1920110

11. Govindarajan, V., \& Srinivas, A. S. (2015, August 30). The innovation mindset in action: $3 M$ corporation. Retrieved from https://hbr. org/2013/08/the-innovationmindset-in-acti-3

12. Hamel, G. (1998, June). The Challenge Today: Changing the Rules of the Game. Business Strategy Review, 9(2), 19-26.

13. Higgins, J. M. (1995). Innovation: The core competence. Strategy \& Leadership, 23(6), 32-36.
14. Jaruzelski, B., Schwarts, K., \& Staach, A. V. (2015). The global innovation 1000 - innovation's new world order. Strategy \& Business, 81, 2-14.

15. Johannessen, J., Olsen, B., \& Lumpkin, G. (2001). Innovation as newness: what is new, how new, and new to whom? European Journal of innovation management, 4(1), 20-31. Retrieved from https:// www.emeraldinsight.com/doi/ abs/10.1108/14601060110365547

16. L. Bottazi, A. P. (2005). The International Dynamics of R\&D and Innovation in the Short and the Long Run. No. w11524. National Bureau of Economic Research.

17. Lundvall, B. A. (2010). National systems of innovation: Toward a theory of innovation and interactive learning (Vol. 2). Anthem Press.

18. McClelland, D. C. (1987). Human motivation. CUP Archive.

19. Potts, H. E. (1994, July). The Definition of Invention in Patent Law. The Modern Law Review, 7, 113-123.

20. Prahalad, G. H. (1989, May/June). Strategic Intent. Harvard Business Review.

21. Roberts, E. B. (1988). What we have learned: Managing Invention and Innovation. Research Technology Management, 1, 11-29. https://doi.org/10.1080/08956308. 1988.11670497 
22. Rogers, E. M. (1995). Diffusion of Innovations (4th ed.). New York: Free Press.

23. Schumpeter, J. A. (2000) Entrepreneurship as Innovation. Entrepreneurship: The Social Science View, 51-75.

24. Skouloudis, A., Evangelinos, K., \& Kourmousis, F. (2009, December 3). Assessing non-financial reports according to the Global Reporting Initiative guidelines: evidence from Greece. Journal of Cleaner Production, 18(5), 426-438.

25. Statista (2017, March). Statista The Statistical Portal. Retrieved from https://www.statista.com/ statistics/271406/advertisingrevenue-of-social-networksworldwide/

26. Strategy \& (2013). Who We Are. Strategye creates strategy that works. Retrieved from Strategy\&: http://www.strategyand.pwc.com/ global/home/who_we_are

27. Strategy \& (2015). Past studies 2005-2013. Retrieved from http:// www.strategyand.pwc.com/ global/home/what-we-think/innovation $1000 /$ past-year-studies (accessed on March 28, 2015).

28. Strategy\& (2017). The top innovators and spenders.
Retrieved from http://www.strategyand.pwc.com/innovation 1000 (accessed on March 28, 2015).

29. Strategy\& (2017, January 3-5). Private Communication.

30. Ven de Van, A. H. (1986). Central problems in the management of innovation. Management Science, 32(5), 590-607.

31. Wang, E. L., \& Kleppe, J. A. (2001). Teaching invention, innovation, and entrepreneurship in engineering. Journal of Engineering Education, 90(4), 565. 